\title{
Determining the Anxiety Levels of Emergency Health Workers in the COVID-19 Pandemic
}

\author{
(1) Ibrahim Özlü${ }^{1}$, (1) Merve Kaya², (1) Zeynep Karaman Özlü³ , (1) Erdal Tekin², (1) Nazım Onur Can ${ }^{4}$ \\ 1Department of Emergency Medicine, Atatürk University Faculty of Medicine, Erzurum, Turkey \\ 2Department of Surgical Nursing, Atatürk University Faculty of Nursing, Erzurum, Turkey \\ ${ }^{3}$ Department of Surgical Nursing, Anesthesiology Clinical Research Office, Atatürk University Faculty of Nursing, Erzurum, Turkey \\ ${ }^{4}$ Clinic of Emergency, Erzurum District Research Hospital, Erzurum, Turkey
}

\begin{abstract}
Aim: This study aimed to determine the anxiety levels of emergency healthcare workers during the coronavirus disease-2019 (COVID-19) pandemic.

Materials and Methods: This descriptive and cross-sectional study was conducted using face-to-face interviews with 153 healthcare workers in emergency service clinics who cared for patients suspected of COVID-19. Study data were obtained using a descriptive characteristics questionnaire and the State-Trait Anxiety Inventory (STAI).

Results: The mean state anxiety score of emergency healthcare workers was $42.76 \pm 10.06$, the mean trait anxiety score was $42.11 \pm 8.22$, and the total scale mean score was $84.88 \pm 15.11$. No significant relationships were found between STAI scores and participants' descriptive characteristics (i.e., workplace, gender, marital status, age, profession, years of experience, and satisfaction with work conditions).

Conclusion: This study revealed that emergency healthcare workers experienced anxiety at the panic level.

Keywords: Anxiety, emergency, COVID-19
\end{abstract}

\section{Introduction}

Humanity has faced disasters throughout history. One type of disaster is epidemic disease, which deeply affect humanity and lead to death and devastating effects. They also disrupt social life and the commercial activities of communities (1). Today's disaster is the novel coronavirus disease-2019 (COVID-19), which emerged in December 2019 in the Wuhan Province of China and went on to affect the entire world. It was determined that this disease is caused by a new type of coronavirus (CoV) that has not been detected before, and it was named SARS-CoV-2 due to its similarity to the Severe Acute Respiratory Syndrome (SARS) virus $(2,3)$. While SARS-CoV-2, a member of the CoV family, is causing a pandemic, the Middle East Respiratory Syndrome (MERS) and SARS have also caused serious infection rates and deaths in the world. In addition, this family has many subtypes (HCoV-229E, HCoV-OC43, HCoV-NL63 and HKU1-CoV), which can be found in people, but are characterized by milder infections $(2,4)$.

As in all epidemics, people's lives have also been turned upside down, and an atmosphere of panic has been created in societies. Despite all protective and isolation measures taken by governments, social psychological trauma could not be prevented. Health workers have found themselves in a more peculiar position in terms of psychological trauma. They not only face normal risks like other people, but also professional risks $(5,6)$. Those who perform invasive procedures such as intubation and resuscitation, bronchoscopy and catheter insertion, and laboratory workers and healthcare workers who are in direct contact with patients constitute the high-risk group. Emergency health workers are thus 
part of the high-risk group for COVID-19. In addition, healthcare workers face problems such as discrimination, exclusion and pressure in society, working above capacity, separation from their families and burnout syndrome. These have led to stress, anxiety and depression (7).

Without doubt, the emergency service workers who first encounter COVID-19 patients are among the groups that have experienced these feelings most intensely during the pandemic. Determining the anxiety levels of the emergency service workers who faithfully struggle with the pandemic, and planning appropriate measures is extremely important both for emergency service workers and for the quality and reliability of the services they provide to the public. Before effective approaches are developed to support health professionals, it is important to determine their anxiety and fear levels (8).

This study aims to determine the anxiety levels of emergency health workers during the COVID-19 pandemic.

\section{Materials and Methods}

\section{Type of Study}

This is a descriptive and cross-sectional study.

\section{Study Population and Sample}

This study was conducted from June $1^{\text {st }}$ to June $30^{\text {th }}, 2020$ by faceto-face interviews with 153 health professionals who deals with suspected COVID-19 patients at the emergency service clinics of Erzurum Atatürk University and Erzurum District Training and Research Hospital. The study population consisted of 184 people who worked in these hospitals during the study period, and the study sample consisted of 153 voluntary participants who agreed to participate in the study. The population representation power of the sample was $83.2 \%$.

\section{Data Collection}

The study data were obtained using a descriptive characteristics questionnaire and the State-Trait Anxiety Inventory (STAI). The participants filled out the forms individually in approximately five minutes.

The Descriptive Characteristics Questionnaire consists of 14 questions regarding the health professionals' age, gender and professional information.

The State-Trait Anxiety Inventory (STAI) was developed by Spielberg et al. (9) in the USA in 1970 and its Turkish form's validity and reliability were performed by Öner and Le Compte (10). This form includes two scales consisting of a total of 40 questions. The first 20 questions measure the state anxiety level of the patient, while the remaining questions measure the trait anxiety levels.
The state anxiety scale requires individuals to determine how they feel at a certain time and under certain conditions and answer the questions considering their feelings under these conditions. The trait anxiety scale requires individuals to determine how they generally feel. While reading the state anxiety scale, in accordance with the strength of the current feelings, patients answered each question with one of the following responses: (1) Never, (2) Some, (3) Much or (4) Completely. They answered each question of the trait anxiety scale with one of these responses: (1) Rarely, (2) Sometimes, (3) Mostly or (4) Almost every time. There are two types of statements on the scales that are either direct or reverse statements. Both the state anxiety and the trait anxiety scales include 10 questions with direct statements and 10 with reverse statements. Direct statements indicate negative feelings, while reverse statements represent positive feelings. When scoring the reverse statements, statements that have a weighted value of 1 become a 4 , and a weighted value of 4 becomes a 1. Furthermore, answers with a value of 4 indicate a high level of anxiety in direct statements, however, in reverse statements, answers with a value of 1 indicate a high level of anxiety. According to Oner's suggestion, on Speilberg's state trait anxiety scale, scores are assessed as follows: 0-19 points indicate "no anxiety", 20-39 points indicate "slight anxiety", 40-59 points indicate "moderate anxiety", 60-79 points indicate "severe anxiety" and scores of 80 and higher represent "panic" $(9,10)$. In this study the Cronbach's alpha internal consistency coefficient was 0.71 .

\section{Statistical Analysis}

All data were analyzed with SPSS (Statistical Package for the Social Sciences) software for Windows (v18.0; IBM, Armonk, NY, USA). Individual and aggregate data were summarized using descriptive statistics including mean, standard deviation, medians (minimum-maximum), frequency distributions and percentages. Initial evaluations and comparison of the data for normal distribution was made via Kolmogorov-Smirnov and Shapiro-Wilk tests. Comparison of the dependent variables with normal distribution was made with Student's t-test and ANOVA. For the continuous variables that were not normally distributed, the Kruskall-Wallis and Mann-Whitney U tests were conducted to compare the groups. The results were evaluated at a $95 \%$ confidence interval, and $p<0.05$ was the threshold for statistical significance.

\section{Ethical Aspects of the Study}

The principles of the Declaration of Helsinki were followed during the study. Approval was obtained from Atatürk University Faculty of Medicine Ethics Committee (no:15, date: 28.05.2020). Information was given to the participants about the purpose of 
the study, its methods and the time they were asked to allocate for the study. Their verbal consent was obtained, after explaining that the data collected would only be used within the scope of the study, and that confidentiality would be strictly ensured.

\section{Results}

The biggest group of the participants (64.7\%) had been working at the district training and research hospital; $57.5 \%$ of the participants were men, and $51.6 \%$ were married. The biggest education group was formed by high school graduates (35.9\%); $39.2 \%$ had worked at the hospital for $1-5$ years, and $28.8 \%$ were nurses. Finally, $82.4 \%$ liked their profession, and $57.5 \%$ were satisfied with their work conditions (Table 1).

The participants' mean state anxiety score was $42.76 \pm 10.06$, and their mean trait anxiety score was $42.11 \pm 8.22$. Their mean score on the entire STAI was $84.88 \pm 15.11$ (Table 2).

Table 3 shows a comparison of STAI mean scores and the participants' descriptive characteristics. No statistically significant relationships were found between the participants' STAI mean scores and their descriptive characteristics (workplace, gender, marital status, age, profession, years in the profession, satisfaction with work conditions).

\section{Discussion}

During epidemics, healthcare workers are in closest contact with infected patients. Healthcare professionals at the forefront of combating the disease in this difficult time have been confronted with a deadly virus with an extremely high rate of contagiousness which has never been seen before. The mental health of healthcare professionals in emergency departments has been significantly affected, and they experience serious difficulties dealing with this complex situation $(11,12)$. The results of the current study are discussed here along with those in the literature.

This study determined that the participants' mean score on the entire STAI was 84.88, which corresponds to panic. Studies have reported that the COVID-19 pandemic has had more psychological effects on healthcare personnel than injuries $(11,12)$. Cheung et al. $(13)$ conducted a study in Hong Kong and found that medical and nursing personnel experienced high levels of burnout, mental fatigue and anxiety due to the COVID-19 pandemic. Bohlken et al. (14) determined that doctors in Germany experienced high levels of anxiety and show depressive symptoms. Unfortunately, previous studies have reported that severe psychological pressure and intense fear of death have even led healthcare personnel to attempt suicide $(15,16)$. Healthcare workers on the frontline in Wuhan were under moderate to severe stress during the peak periods of the epidemic, and many reported high anxiety levels and depression (17). Regarding this subject, another study conducted in Wuhan, the main center of the epidemic, reported that a large proportion of healthcare workers experienced severe anxiety and most of them received psychological help (18). Chew et al. (19) conducted a multi-center study and found that $8.7 \%$ of healthcare personnel experienced anxiety on levels from moderate to panic. The results of this

Table 1. Distribution of the emergency health professionals' descriptive characteristics

\begin{tabular}{|c|c|c|}
\hline Characteristics & Number & Percentage \\
\hline \multicolumn{3}{|l|}{ Hospital } \\
\hline District Research Hospital & 99 & 64.7 \\
\hline Atatürk University Research Hospital & 54 & 35.3 \\
\hline \multicolumn{3}{|l|}{ Gender } \\
\hline Female & 65 & 42.5 \\
\hline Male & 88 & 57.5 \\
\hline \multicolumn{3}{|l|}{ Marital status } \\
\hline Married & 79 & 51.6 \\
\hline Single & 74 & 48.4 \\
\hline \multicolumn{3}{|l|}{ Education } \\
\hline Primary school graduate & 6 & 3.9 \\
\hline High school graduate & 55 & 35.9 \\
\hline Associate's degree & 25 & 16.4 \\
\hline Bachelor's degree & 32 & 20.9 \\
\hline Master's degree & 35 & 22.9 \\
\hline \multicolumn{3}{|l|}{ Years of work experience } \\
\hline $1-5$ years & 60 & 39.2 \\
\hline $6-10$ years & 53 & 34.6 \\
\hline 11 years and more & 40 & 26.1 \\
\hline \multicolumn{3}{|l|}{ Profession } \\
\hline Physician & 39 & 25.5 \\
\hline Nurse & 44 & 28.8 \\
\hline Emergency medical technician & 13 & 8.5 \\
\hline Triage staff & 6 & 3.9 \\
\hline Personnel (cleaning and transport) & 21 & 13.7 \\
\hline $\begin{array}{l}\text { Other (medical secretary, X-ray } \\
\text { technician, etc.) }\end{array}$ & 30 & 19.6 \\
\hline \multicolumn{3}{|l|}{ Are you happy with your job? } \\
\hline Yes & 126 & 82.4 \\
\hline No & 27 & 17.6 \\
\hline \multicolumn{3}{|c|}{ Are you satisfied with your work conditions? } \\
\hline Yes & 65 & 42.5 \\
\hline No & 88 & 57.5 \\
\hline Age [Mean (SD)] & \multicolumn{2}{|c|}{$30.96 \pm 7.13$} \\
\hline SD: Standard deviation & & \\
\hline
\end{tabular}


Table 2. Minimum and maximum scores on the State-Trait Anxiety Inventory (STAI) and the distribution of mean scores

\begin{tabular}{|l|l|l|}
\hline Subdimension & Min-max scores & Mean scores $\overline{\mathbf{X}} \pm$ SD \\
\hline State Anxiety Scale & $20-65$ & $42.76 \pm 10.06$ \\
\hline Trait Anxiety Scale & $21-72$ & $42.11 \pm 8.22$ \\
\hline STAI Score & $41-125$ & $84.88 \pm 15.11$ \\
\hline SD: Standard deviation & \\
\hline
\end{tabular}

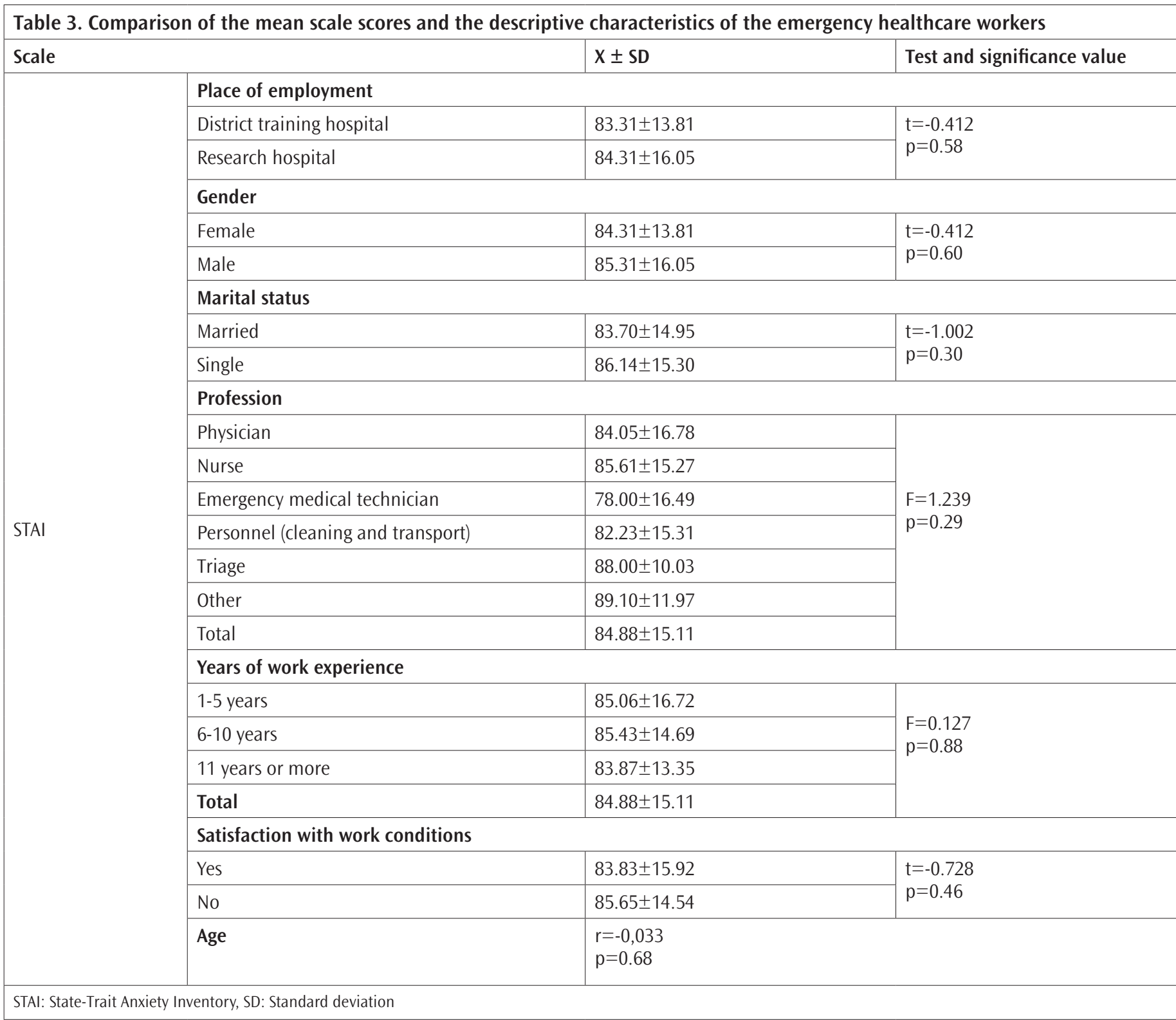

study are consistent with the international literature. Emergency departments are first groups to come into contact with people infected with COVID-19, and many aspects of the disease that are not yet fully understood, the fear of death and intense work conditions cause them to experience panic level anxiety. At the same time, the fear of transmitting the virus to their families and necessity of staying away from their families during this time is thought to be another reason for intense stress. News about healthcare workers in other countries going through very difficult times due to severe work conditions, also increased the anxiety levels of emergency health personnel.The anxiety levels of this study's participants did not vary with sociodemographic 
variables such as age, gender, marital status or profession. Huang and Zhao reported that young people in China experienced more fear of catching the disease, and that their anxiety levels were higher (20). The first scientific study of the anxiety levels of healthcare professionals in Wuhan reported that female healthcare professionals experienced more fear than their male counterparts (17). A study conducted in Turkey found that nurses experienced more anxiety than other healthcare personnel, and that female healthcare workers experienced more anxiety than males (21). Another study determined that approximately one-third to half of nurses had symptoms of anxiety, depression and insomnia. It also reported that, like nurses, physicians experienced great levels of stress, and that nearly half of them experienced anxiety and depression (22). This study's results differ from those in the literature. This may be due to the panic level anxiety of this study's participants. Because all groups had high levels of anxiety, mean score of the whole population was found at panic level. In addition, this result may be due to the fact that the study was conducted when the pandemic reached high levels and awareness of all groups increased as the epidemic had spread and become a more severe pandemic. The literature describes four levels of anxiety: mild, moderate, severe and panic. At the panic level, responsiveness to external stimuli decreases, motor coordination weakens, and communication problems occur. In addition, problems such as dyspnea, dizziness and fear of death may occur (23). Panic level anxiety negatively affects all personnel, regardless of age, gender, marital status or profession. This study shows how seriously this epidemic has affected emergency healthcare professionals who are in constant contact with infected patients, who are the first group to interact with them and who are at risk of being infected.

\section{Study Limitations}

The study was conducted in the center, and the study sample reflects only one area of Turkey. The results of this study can be generalized to the study group.

\section{Conclusion}

The results of the study indicate that the emergency healthcare workers experienced anxiety at the panic level. Anxiety affects mental status and can cause serious problems for the short- and long-term psychological well-being of emergency health care personnel. It is extremely important to evaluate anxiety levels in order to provide an effective support system for emergency health personnel, to begin their psychological recovery process as soon as possible and to meet their psychological care needs.

In order to protect the mental health of emergency medical personnel, psychological counseling and group meetings should be provided to address and manage methods of coping with the anxiety caused by this pandemic.

\section{Acknowledgements}

The authors wish to thank and acknowledge the participants for sharing their experiences with us.

\section{Ethics}

Ethics Committee Approval: The principles of the Declaration of Helsinki were followed during the study. Approval was obtained from Atatürk University Faculty of Medicine Ethics Committee (no:15, date: 28.05.2020).

Informed Consent: Information was given to the participants about the purpose of the study, its methods and the time they were asked to allocate for the study. Their verbal consent was obtained, after explaining that the data collected would only be used within the scope of the study, and that confidentiality would be strictly ensured.

Peer-review: Externally peer-reviewed.

\section{Authorship Contributions}

Conception and Design: I.Ö., M.K., Z.K.Ö., Data Analysis and/or Interpretation: I.Ö., E.T., Z.K.Ö., M.K., Statistical Analysis: I.Ö., Writing: I.Ö., Z.K.Ö., E.T., M.B., N.O.C.

Conflict of Interest: No conflict of interest was declared by the authors.

Financial Disclosure: The authors declared that this study received no financial support.

\section{References}

1. Rawls CG, Turnquist MA. Pre-positioning of emergency supplies for disaster response. Transportation Research Part B: Methodological. 2010;44:521-34.

2. Zhu N, Zhang D, Wang W, Li X, Yang B, Song J, et al. A Novel Coronavirus from Patients with Pneumonia in China, 2019. N Engl J Med. 2020;382:727-33.

3. TR Ministry of Health, General Directorate of Public Health. COVID-19 guide. Ankara: Ministry of Health, General Directorate of Public Health. 2020.

4. Mousavizadeh L, Ghasemi S. Genotype and phenotype of COVID-19: Their roles in pathogenesis. J Microbiol Immunol Infect. 2021;54:159-63.

5. Rajkumar RP. COVID-19 and mental health: A review of the existing literature. Asian J Psychiatr. 2020;52:102066.

6. Ekiz T, Ilıman E, Donmez E. Comparison of health anxiety level and control perception of COVID-19 Int J Healthc Manag and Strategies Research. 2020;6:139-54.

7. Kang L, Li Y, Hu S, Chen M, Yang C, Yang BX, et al. The mental health of medical workers in Wuhan, China dealing with the 2019 novel coronavirus. Lancet Psychiatry. 2020;7:e14.

8. White DB, Lo B. A Framework for Rationing Ventilators and Critical Care Beds During the COVID-19 Pandemic. JAMA. 2020;323:1773-4

9. Spielberger CD, Gorsuch RL, Lushene RE. Test manual for the State Trait Anxiety Inventory. 1st ed. California: Consulting Psychologists Press, 1970.

10. Öner N, Le Compte A. Discontinuous (state) trait anxiety inventory handbook, 2nd Edition, Istanbul, Boğaziçi University Publications. 1983;1-26. 
11. Pappa S, Ntella V, Giannakas T, Giannakoulis VG, Papoutsi E, Katsaounou P. Prevalence of depression, anxiety, and insomnia among healthcare workers during the COVID-19 pandemic: A systematic review and meta-analysis. Brain Behav Immun. 2020;88:901-7.

12. Zhang WR, Wang K, Yin L, Zhao WF, Xue Q, Peng M, et al. Mental Health and Psychosocial Problems of Medical Health Workers during the COVID-19 Epidemic in China. Psychother Psychosom. 2020;89:242-50.

13. Cheung T, Fong TKH, Bressington D. COVID-19 under the SARS Cloud: Mental Health Nursing during the Pandemic in Hong Kong. J Psychiatr Ment Health Nurs. 2021;28:115-7.

14. Bohlken J, Schömig F, Lemke MR, Pumberger M, Riedel-Heller SG. COVID-19Pandemie: Belastungen des medizinischen Personals [COVID-19 Pandemic: Stress Experience of Healthcare Workers - A Short Current Review]. Psychiatr Prax. 2020;47:190-7.

15. Papoutsi E, Giannakoulis VG, Ntella V, Pappa S, Katsaounou P. Global burden of COVID-19 pandemic on healthcare workers. ERJ Open Res. 2020;6:001952020.

16. Montemurro N. The emotional impact of COVID-19: From medical staff to common people. Brain Behav Immun. 2020;87:23-4.

17. Du J, Dong L, Wang T, Yuan C, Fu R, Zhang L, et al. Psychological symptoms among frontline healthcare workers during COVID-19 outbreak in Wuhan. Gen Hosp Psychiatry. 2020;67:144-5.
18. Kang L, Ma S, Chen M, Yang J, Wang Y, Li R, et al. Impact on mental health and perceptions of psychological care among medical and nursing staff in Wuhan during the 2019 novel coronavirus disease outbreak: A cross-sectional study. Brain Behav Immun. 2020;87:11-7.

19. Chew NWS, Lee GKH, Tan BYQ, Jing M, Goh Y, Ngiam NJH, et al. A multinational, multicentre study on the psychological outcomes and associated physical symptoms amongst healthcare workers during COVID-19 outbreak. Brain Behav Immun. 2020;88:559-65.

20. Huang Y, Zhao N. Generalized anxiety disorder, depressive symptoms and sleep quality during COVID-19 outbreak in China: a web-based crosssectional survey. Psychiatry Res. 2020;288:112954.

21. Hacimusalar Y, Kahve AC, Yasar AB, Aydin MS. Anxiety and hopelessness levels in COVID-19 pandemic: A comparative study of healthcare professionals and other community sample in Turkey. J Psychiatr Res. 2020;129:181-8.

22. Que J, Shi L, Deng J, Liu J, Zhang L, Wu S, et al. Psychological impact of the COVID-19 pandemic on healthcare workers: a cross-sectional study in China. Gen Psychiatr. 2020;33:e100259.

23. Öz F. Basic Concepts in Health. 2nd Edition. Ankara: Mattek Printing House; 2010. p. 130-5 